\title{
A HISTÓRIA ORAL PARA TRAZER À TONA ASPECTOS DA IDENTIDADE DOCENTE
}

\author{
ORAL HISTORY TO BRING OUT ASPECTS OF TEACHING IDENTITY \\ HISTORIA ORAL PARA PRESENTAR ASPECTOS DE IDENTIDAD DOCENTE
}

\author{
Simone Gomes de Faria \\ Mestre em História. Professora da Rede Municipal de Bagé e Hulha Negra. \\ Universidade Federal de Pelotas/ RS \\ e-mail: simonegomesdefaria@gmail.com
}

\author{
Adriana Kivanski de Senna \\ Doutorado em História pela Pontifícia Universidade Católica do Rio Grande do Sul. Professora associada da \\ Universidade Federal do Rio Grande. \\ e-mail: akivanski@hotmail.com
}

\begin{abstract}
Resumo
O ensaio é dividido em três momentos: primeiramente enfocamos acerca da história da História Oral para fornecer ao leitor um parâmetro geral enquanto campo de constituição; na sequência se conceitua a História Oral onde se ampara de Delgado (2006), Verena Alberti (2004), Meihy e Ribeiro (2011), Thompson (1992); Portelli (1991) , ou seja, estas referências sustentam a linha de pensamento fundante sobre o que significa este aporte metodológico; nos momentos finais equaciona-se aspectos que podem amparar futuras investigações que se apropriem da $\mathrm{HO}$ na construção da identidade docente. Assim, o objetivo central do trabalho é o de incentivar aos pesquisadores da História da Educação a cercearem-se deste instrumento como um veio para detectar as singulares culturas das práticas escolares dos professores nas diversas instituições educacionais. O aporte metodológico é de cunho qualitativo tendo como fonte de análise as referências bibliográficas. Ademais, justificamos a análise desde porque a partir de 1980 as pesquisas incluem a História Oral como um potente campo para se aferir as experiências e as memórias de docentes rompendo o viés tradicional de narrativa para oportunizar que estes protagonistas deem voz as suas históricas que são particulares, infinitas e ininterruptas, bem como, oportuniza uma abertura para novas problematizações. Em linhas conclusivas, trabalhos que se amparem do método possibilitam que os pesquisadores da área atuem em duas operações epistemológicas: o de compreender e interpretar a identidade docente através de suas trajetórias de vida encetando aspectos dos itinerários dos professores ao longo de diferentes tempos e espaços escolares.
\end{abstract}

Palavras-chave: Metodologia de pesquisa. História da formação de professores. História da Educação.

\footnotetext{
Abstract

The essay is divided into three moments: first it focuses on the history of Oral History to provide the reader with a general parameter as a field of constitution; next, Oral History is conceptualized, supported by Delgado (2006), Verena Alberti (2004), Meihy and Ribeiro (2011), Thompson (1992); Portelli (1991), that is, these references support the founding line of thought about what this methodological contribution means; in the final moments, aspects that can support future investigations that take ownership of $\mathrm{HO}$ in the construction of the teaching identity are considered. Thus, the main objective of the work is to encourage
} 
researchers in the History of Education to surround themselves with this instrument as a means of detecting the unique cultures of school practices of teachers in different educational institutions. The methodological contribution is of a qualitative nature, having bibliographical references as source of analysis. Furthermore, the analysis is justified since, since 1980, research has included Oral History as a powerful field to gauge the experiences and memories of teachers, breaking the traditional narrative bias to make it possible for these protagonists to give voice to their histories that they are private, infinite and uninterrupted, as well as providing opportunities for opening up new problems. In conclusive lines, works supported by the method enable researchers in the field to act in two epistemological operations, such as understanding and interpreting the teaching identity through their life trajectories, introducing aspects of the teachers' itineraries over different school times and spaces. .

Keywords: Research methodology. History of teacher education. History of Education.

\section{Resumen}

El ensayo se divide en tres momentos: primero se centra en la historia de la Historia Oral para proporcionar al lector un parámetro general como campo de constitución; luego, se conceptualiza la Historia Oral, apoyada por Delgado (2006), Verena Alberti (2004), Meihy y Ribeiro (2011), Thompson (1992); Portelli (1991), es decir, estas referencias apoyan la línea de pensamiento fundacional sobre lo que significa esta contribución metodológica; En los momentos finales, se consideran aspectos que pueden apoyar futuras investigaciones que se apropian de $\mathrm{HO}$ en la construcción de la identidad docente. Por lo tanto, el objetivo principal del trabajo es alentar a los investigadores de la Historia de la Educación a rodearse de este instrumento como un medio para detectar las culturas únicas de las prácticas escolares de los docentes en diferentes instituciones educativas. La contribución metodológica es de naturaleza cualitativa, teniendo referencias bibliográficas como fuente de análisis. Además, el análisis está justificado ya que, desde 1980, la investigación ha incluido la Historia Oral como un campo poderoso para medir las experiencias y recuerdos de los maestros, rompiendo el sesgo narrativo tradicional para que estos protagonistas puedan dar voz a sus historias que son privados, infinitos e ininterrumpidos, y brindan oportunidades para abrir nuevos problemas. En líneas concluyentes, los trabajos apoyados por el método permiten a los investigadores en el campo actuar en dos operaciones epistemológicas, como comprender e interpretar la identidad docente a través de sus trayectorias de vida, introduciendo aspectos de los itinerarios de los docentes en diferentes tiempos y espacios escolares

Palabras clave: Metodología de investigación. Historia de la formación del profesorado. Historia de la educación.

\section{Introdução}

O uso da História Oral por muito tempo foi preconizado com desdém pelos historiadores clássicos por considerarem o trabalho com a memória como algo sem veracidade. As narrativas de pessoas excluídas eram pormenorizadas, pois, foi somente na contemporaneidade que nos é desvelado uma nova forma de conhecimento histórico não somente baseado em grandes homens e fatos, e sim, uma análise que engloba as estruturas, os processos históricos onde a narrativa sofre mudanças, dando voz para as mulheres, homossexuais, africanos, indígenas, pessoas portadoras de necessidade 
especiais, entre outros, que foram silenciados, isto é, como a corrente historiográfica francesa denomina de uma contra história.

$\mathrm{Na}$ atualidade, analisar as experiências e práticas dos professores tem se tornado uma temática que tem ganhado relevo dentro dos lócus acadêmicos. Deste modo, compreender a construção da identidade docente mediado pela História Oral é um rico instrumento para captarmos inúmeras informações, ainda que, há óticas dentro desta carreira, como as práticas escolares, que não podem ser obtidas somente em documentos escritos.

Destarte, quando lidamos com a subjetividade é imprescindível vislumbrarmos que ela é embasada na experiência de vida de alguém, pois, o agente pesquisado narra os fatos de sua vida tanto na esfera pessoal como social, posto que, todos nós apresentamos histórias de vida que são testemunhos edificados consoante as nossas experiências, o que por si só, constitui um grande campo para a concretização de qualquer pesquisa histórica.

Para tanto, é fundamental que referendamos a memória como uma fonte para as investigações em história da educação com o objetivo de favorecer na compreensão e interpretação dos fatos, e que por sua vez, nos forneça credibilidade para exposição destes.

Entrementes, o presente ensaio de natureza reflexiva pretende primeiramente suscitar informações acerca da história da História Oral em um panorama que vai do internacional para o nacional. Após a análise cronológica faremos um breve diálogo conceituando o que é História Oral para revelarmos os pontos positivos que o uso do método apresenta em trabalhos acadêmicos que almejam suscitar aspectos da cultura material escolar que compõe a formação da identidade docente. Para isso, realizamos um diálogo com importantes referentes na área da História Oral para conceitualizá-lo enquanto método de pesquisa. E, por fim, apontamos a importância do uso do método para investigações na área da História da Educação que tenham como categoria de análise da construção da identidade docente.

\section{A história da História Oral}


É sabido que com o advento e aumento das tecnologias da informação e da comunicação, as investigações históricas, como em outras áreas de saber vêm ocupando um local de destaque nas difusões do conhecimento em torno da oralidade, principalmente, com o avanço em pesquisas da área em História da Educação que se amparam da operação historiográfica da Nova História Cultural.

De acordo com as premissas teóricas de Joutard11 (1998) é importante que façamos um bom uso das evoluções tecnológicas para alcançarmos resultados positivos nas pesquisas que se apropriam desse método. Nesse aspecto, a Universidade de Columbia está diretamente atrelada ao uso do gravador que viabilizou a captura sonora, que até então, não houvera antes de 1950. A esse instrumento deve-se a importância de um salto propulsor relacionado às técnicas que eram utilizadas pelos pesquisadores adeptos do método.

Nesse limiar, o gravador serviu para viabilizar a captura sonora, bem como, para se interpretar as diferentes formas de manifestação do tom da fala; possibilitou a extração de férteis conclusões através das expressões, das hesitações, da linguagem do corpo, dos lapsos de memória e dos silenciamentos oportunizando conhecer de modo mais profícuo as ações vivenciadas pelos entrevistados.

Outrossim, gostaríamos de ressaltar que por meio da evolução tecnológica que nos foi possibilitada um novo olhar para a História Oral. Assim, nem todo tipo de comunicação é uma via tecnológica porque é medular que as pessoas se comuniquem, contudo, os recursos tecnológicos servem como um meio para possibilitar uma melhoria nas investigações. No entanto, o papel da comunicação ainda é essencial para desvelar o porquê de determinados acontecimentos nas mais diversas esferas sociais.

Inegavelmente, tal método de pesquisa foi visto pelos historiadores, principalmente os positivistas e tradicionais, como um procedimento muito subjetivo, destarte, por muito tempo foi alvitrado preconceituosamente.

A assertiva advinda dos aportes teóricos de Portelli (1991) nos revela que a subjetividade é advinda da memória, que por sua vez, podem ser fantasiosos e falíveis não se constituindo em dado preciso, embora, muitas vezes se a utiliza porque nem sempre conseguimos as informações necessárias em documentos escritos. Desta forma,

${ }_{1}^{1}$ Philippe Joutard foi o percussor das premissas teóricas da História Oral na França. Atualmente é Professor de História na Universidade de Provence e da Ecole des Hautes Etudes em Ciências Sociais. 
para corroborar com essa proposição, nos apropriamos da voz de Joutard (1998) que nos aduz que a narrativa oral e a escrita são fontes que estão imbricadas, pois, uma completa a outra nos estudos de investigações científicas.

Analisando diacronicamente o desenvolvimento metodológico da História Oral se apreende que seu surgimento informal remonta a Antiguidade Grega com os cabeças, Heródoto e Tucícledes, entretanto, foi muito resistida pelos positivistas ao longo do tempo. Desde o século XVII a História Tradicional vem se opondo a fonte oral, como nos elucidam Matos e Senna (2011). Entretanto, na França no século XX, se instaura um movimento reacionário ao paradigma historiográfico tradicional com o escopo central de modificar a teoria da História.

No artigo "Aos cinquenta anos: uma perspectiva internacional da história oral”, um dos capítulos do livro História oral: desafios para o século XXI do pesquisador Alistair Thomson ${ }^{2}$ nos desvela que a História Oral nasceu em 1948 pelo americano Allan Nevins 3 que pesquisava as memórias de personalidades importantes dos Estados Unidos. Logo após começa a surgir vários movimentos em torno do uso da História Oral, principalmente, em países da Europa Ocidental e Estados Unidos.

Neste momento, pesquisadores começam a realizar debates fecundos, tal como, seminários e algumas revistas especializadas neste aporte teórico. Como já foi apontado, a Universidade de Columbia dos Estados Unidos foi a pioneira no uso da História Oral devido o surgimento do gravador e, posteriormente essa operação acaba sendo amplamente divulgada na Europa com o intuito de versar acerca dos grandes heróis, dos aspectos da História Política e dos personagens principais dos Estados Unidos da América.

Em 60, a História Oral se torna um importante instrumento empregado por jovens pesquisadores que visavam alterar o estatuto dos paradigmas teóricos até então vigentes, pois:

Nos anos Kennedy, mais do que o choque da Guerra Vietnã - a não ser sob a forma indireta do "terceiro mundismo" -, a descoberta da

\footnotetext{
2Professor e historiador de grande renome internacional da Universidade de Sussex, Inglaterra e membro do Conselho da Associação Internacional de História Oral (IOHA) de 1996 a 2000. Pesquisa com afinco as ideias de veteranos de guerra e de migrantes, bem como, disserta sobre o método da História de vida da pesquisa oral.

3 Josepeh Allan Nevins foi um grande jornalista americano e historiador. Durante sua vida se dedicou a estudar as histórias da Guerra Civil e, principalmente, biografar grandes personalidades como Henry Ford, Hamilton Fish, Groves Cleveland e Rockefeller. Desta forma, é considerado o primeiro historiador a se apropriar da História Oral de forma institucionalizada na denominada Universidade de Columbia nos Estados Unidos.
} 
“outra América", da pobreza, e a expansão do movimento negro desencadeiam o interesse pelos excluídos, pelas minorias étnicas, imigrantes e delinquentes. (FERREIRA, 1994, p.21)

A fala acima nos esclarece que é na década de 60 que nos Estados Unidos os olhares se voltam para uma contra história, ou seja, uma história que até então era vista de baixo. Neste mesmo período, na Europa, antropólogos, sociólogos deram início às incipientes discussões ao redor da evidência histórica e o uso da memória foram muito encetadas, pois, o certame do momento postulava que com o passar do tempo essa apresentaria lacunas que poderia desestabilizar a Ciência Histórica.

Ainda, na Itália se estabelece uma segunda geração de historiadores orais como nos elucida Matos e Senna (2011). Esses tinham como cerne principal refazer as construções representadas pela cultura popular embasados em testemunhos orais sendo o cenário ideal para uma observação mais atenta das singularidades da História Oral como fonte.

Nesse ínterim, com a Micro-História e a Nova História Cultural emergem viáveis alternativas para a utilização dos recursos memorialistas que se cerceavam deste método para constituir uma nova história propugnada pelos sindicalistas e feministas em 1968. Em suma, foi criada uma nova história, modificaram-se as tradicionais correntes historiográficas passando a direcionar novos olhares e perspectivas, tais como: questões de gênero, setores populares, pessoas com necessidades especiais, religião, transnacionalismo e transculturalismo, operários, as mulheres, o cerne social, entre outras temáticas de pesquisa.

$\mathrm{Na}$ fase posterior de historiadores orais, em 1970, acontece um "boom" de pesquisas que se aportavam do método, principalmente, em investigações que primavam pela utilização de histórias de vida tanto na Europa como nos Estados Unidos. Tem-se como expoente, na França - Alexandre Joutard - desenvolvendo pesquisas relacionadas ao redor de etno-textos e da previdência social conforme nos alude Matos e Senna (2011), da mesma maneira, a Grã-Bretanha assume como expoente na área Paul Thompson que aponta que "a função da História Oral, ao devolver a história do povo, é de democratizar a própria história.” (FERREIRA, 1994, p. 29) 
Em 1990, surge à quarta geração de historiadores orais, as proposições mais consistentes estavam atreladas às experiências e as possibilidades de mudanças viáveis mediante ao uso da fonte oral. Nessa perspectiva apontada, de acordo com os acontecimentos do período foi organizada teoricamente e metodologicamente e passa a ser denominada de História Oral.

$\mathrm{Na}$ América Latina, a História Oral, tem um percurso diferente dos países Europeus e dos Norte-Americanos. Embora essa surgisse na década de 70 com temáticas que eram alicerçadas pela história política e pela antropologia o seu desenvolvimento só viera a ocorrer após o período da redemocratização nos países que vivenciaram as Ditaduras Militares, pois, nessa década ainda era amplamente preconizado o uso de fontes escritas com base em informações analíticas, e por sua vez, o uso da oralidade não apresentava nenhum prestígio nos meios acadêmicos.

América Latina, desencadeou um processo de dependência com relação aos países de primeiro mundo ao incorporar as ideias de seus colonizadores. Além disso, tornou a Europa como centro de referência e inspiração do saber acarretando várias disputas arguitivas entre os resistentes conservadores e os progressistas libertários. Partindo deste pressuposto, o surgimento desse método necessita de novas abordagens e soluções do que os apresentados pela Europa e pelos Estados Unidos.

É dentro deste contexto explicitado acima que o Brasil se enquadrou nos parâmetros da história mundial lhe sendo negada a tradição oral porque o instrumento mais utilizado pelos dominadores foi a perpetuação do analfabetismo, o que assolou uma História de alienação e de dependência política.

Convém expor que os países do "Sul" se alicerçaram de uma sofisticada fundamentação teórica em face de um complexo engendramento político local. Dessa maneira, houve uma sinopse dos textos advindos dos países do primeiro mundo para que houvesse uma readaptação consoante a própria localidade.

No Brasil, a História Oral, começa a ser sistematizada por Aspásia Camargo, em 1975, com o projeto de pesquisa intitulado "Trajetória e desempenho das elites políticas brasileiras", com o intuito de registrar o depoimento de pessoas que haviam sido partícipes da história política do país na década de 30 a fim de compreender as transformações deste período, quer dizer, o processo de consolidação do Estado 
brasileiro até a Ditadura de Militar de 1964. No entanto, tal sistematização pela pesquisadora foi possível "a partir de cursos fornecidos por especialistas mexicanos e norte-americanos na Fundação Getúlio Vargas, no Rio de Janeiro" conforme nos revela Ferreira (1994, p.09). Partindo deste fato sua definição começa a ganhar contornos partir de 1979 e o seu robustecimento vem a ocorrer somente depois de 1983 no processo de redemocratização política do país com o intuito de ser uma nova voz nos debates democráticos que foi inspirada nos moldes da Universidade de Columbia dos Estados Unidos e coordenado pelo grupo alcunhado de C.P.D.O.C ${ }^{4}$ patrocinado pela Fundação Ford.

Mesmo após a redemocratização, não houve grandes mudanças, apenas alguns breves debates que ainda tencionavam a prezar a produção estrangeira e não valorizar a local. Desta forma, o método esteve mais imbricado com os interesses de jornalistas, sociólogos, antropólogos e psicólogos devido ao fato que a instabilidade política ainda influenciava o cenário nacional até metade da década de 1980.

Segundo as premissas teóricas de Ferreira (1994) na década de 1980 os pesquisadores que adentravam no terreno da História Oral:

eram predominantemente cientistas sociais, constatou-se uma maioria de historiadores, com $51 \%$ ficando os cientistas sociais em segundo lugar, com $34 \%$. A seguir vinham os profissionais das áreas de educação e letras, com $3,7 \%$ e, finalmente, das áreas de enfermagem, psicologia e saúde pública, com 1,8\% cada. (FERREIRA, 1994, p.08)

Os dados demarcados pela pesquisadora nos revelam que havia uma diversidade de estudiosos interessados na apropriação deste método, no entanto, até então era domínio maior dos historiadores. Apesar disso, é em 1980, que se expande as temáticas abordadas como "a classe trabalhadora brasileira, a história de bairros, as minorias e grupos discriminados, como negros e mulheres." (FERREIRA, 1994, p.11)

\footnotetext{
4 É o Centro de Pesquisa e Documentação de História Contemporânea do Brasil, criada em 1973, tem como escopo primordial abrigar conjuntos de documentos da História do Tempo Presente pertencente à Escola de Ciências Sociais da Fundação Getúlio Vargas. Vale expor que há quase dois milhões de documentos de personalidade pública, assim sendo, convém ressaltar que o centro tendia a dar primazia para a elite nacional. Segundo Verena Alberti (2004) "o programa procurou conjugar duas tendências no desenvolvimento da história oral: de um lado, a norte-americana, que privilegiava a formação de bancos de depoimentos orais, sem que sua produção se subordinasse necessariamente a um projeto de pesquisa, e, de outro, a europeia, que privilegia a lógica da investigação científica, sem que as entrevistas dela resultantes fossem necessariamente colocadas à disposição de um público de pesquisadores.”
} 
Ademais, um dos pontos mais significativos para que isso ocorresse advinha do fato que as Universidades estavam em calamidade pública devido à Ditadura Militar, da mesma forma que, muitas não executaram suas atividades acadêmicas dificultando o acesso de referências bibliográficas específicas ao método e, muitas das existentes, não havia traduções corretas dos grandes pesquisadores teóricos na área.

Desde a sua origem, a História Oral, foi instituída com o teor militante, os depoimentos mais recorrentes na ditadura advieram dos militares e da elite política e cultural da época. A História Oral entra em cena com o intuito de dar mais emoção a toda aquela gama de escritos frios, dado que, após o período ditatorial há muitos documentos secretos que não traziam informações almejadas por muitas vezes serem somente um amontoado de papéis havendo uma necessidade de desvelar a memória de esferas que tencionassem que a população se esquecesse, e assim, se silenciassem.

Nesse entremeio de acontecimentos onde os países necessitam de afirmação houve $\mathrm{o}$ anseio de surgir pesquisas orais com crianças, mulheres, analfabetos, camponeses, marginalizados sociais, africanos, indígenas, imigrantes, operários, pessoas portadoras de necessidades especiais, carnavalescos, militares de esquerda, pessoas doentes, pessoas comuns, presos políticos partindo do local para o âmbito nacional.

Outra marca importante na História Oral brasileira, muito abordada em estudos, está intrínseca ao Movimento dos Trabalhadores Rurais sem Terra (MST), do mesmo jeito que, narrativas extraídas de imigrantes e migrados de diversas nacionalidades. Tais temas continentes estão se desenvolvendo e sendo amplamente utilizados em projetos que visam o desenvolvimento agrário e aqueles que versam a respeito da identidade, etnicidade, cultura, entre outros.

Um ponto que deve ser discutido, principalmente, na contemporaneidade é a de que devemos retirar de cena as mentalidades impostas por nossos colonizadores criando diálogos teóricos que contribuam para o desenvolvimento da técnica ou método da oralidade, pois, nossa imagem já está totalmente arraigada a pobreza, a violência, a marginalização e as fortes repressões ditatoriais competindo aos Historiadores latinoamericanos se engajarem na luta de recuperar as memórias oprimidas, ocultas e totalmente silenciadas. 
Atualmente, a História Oral latino-americana se encontra em estado germinal, tem se destacado e com um aumento bastante significativo apresentando estudos de grande qualidade e originalidade, tal como, há o surgimento de várias revistas acadêmicas interpelando sobre o assunto, não obstante, essa tendência oral por muito tempo foi fixada somente em instituições de Ensino Superior.

Nos dias atuais houve um avanço muito grande, principalmente porque já nasceu muito tarde e foram ampliados para espaços populares, arquivos, movimentos sociais, setores sociais com o desígnio central de reaver as histórias contadas das adversas trajetórias sociais. Porém, se denota que os países latino-americanos apresentam um contexto muito diferente porque há alguns em desenvolvimento e, outros ainda estão engatinhando para compreender e empreender os usos da História Oral em suas investigações.

A configuração do método na América Latina foi muito diferente do que nos países de primeiro mundo dada como um reflexo de um determinado momento histórico, em resumo, a sua institucionalização decorre com o caráter explicativo para que houvesse uma compreensão de como se encontrava a sociedade brasileira apontando uma reconfiguração para as Políticas Púbicas Brasileiras.

Passado este aporte de como se fora constituindo o campo de estudo definiremos alguns aspectos importantes para levantarmos questões acerca do que é a História Oral enquanto método exponencial que amplia o leque de possibilidades acadêmicas que entabulam projetos relacionados com construção da identidade docente por meio do uso metodológico da História Oral.

\section{Conceituando a História Oral}

Há muitas definições para a História Oral, no entanto, tomemos para nós a que nos relata que é "um procedimento metodológico que busca, pela construção de fontes e documentos, registra, através de narrativas induzidas e estimuladas, testemunhos, versões e interpretações sobre a História em suas múltiplas dimensões" (DELGADO, 2006, p.15).

Lucília Delgado (2006), em sua fala acima, nos expõe que à medida que um novo 
questionamento vem sendo realizado com relação ao passado é necessário que se empregue outros métodos com o objetivo de compreendermos informações que não se encontram ancorados em documentos escritos servindo como um importante registro da memória.

A assertiva acima pode ser fortalecida com a voz de Verena Alberti (2004) que nos revela que "a entrevista de história oral permite também recuperar aquilo que não encontramos em documentos de outra natureza: acontecimentos pouco esclarecidos ou nunca evocados, experiências pessoais, impressões particulares, etc." Para tanto, devemos tomar consciência que a peça chave das pesquisas realizadas com História Oral não é somente a criação de documentos inexistentes, mas sim, dar a estes documentos organicidade as diferentes versões apontadas em outros estudos, em especial, àquelas pesquisas que se amparam de documentos escritos.

Para seguirmos os enfoques apontados por Delgado (2006) e Alberti (2004) nos apropriamos da voz de Meihy e Ribeiro (2011) que nos aduz que "História oral é um conjunto de procedimentos que se iniciam com a elaboração de um projeto e que continua com a definição de um grupo de pessoas a serem entrevistado." (MEIHY E RIBEIRO, 2011, P.12) Os autores colocam em xeque uma questão muito importante, isto é, falar em entrevista nem sempre significa que estejamos realizando uma História Oral porque ela pode ser simples, isolada, única ou até mesmo não serem gravadas como os autores Meihy e Ribeiro (2011, p.13) nos esclarecem, já que, as entrevistas que contemplam a História Oral são aquelas derivadas de um projeto de pesquisa quer seja ele acadêmico ou institucional.

Em epítome, "a entrevista em história oral é a sistematização dos processos organizados pela lógica proposta no projeto inicial. Entende-se por projeto o plano capaz de articular argumentos operacionais de ações desdobradas de planejamentos de pesquisas prévias sobre algum grupo social que tem algo a dizer. Pode-se afirmar que sem projeto não há história oral." (MEIHY; RIBEIRO, 2011, p.13) Assim, todo projeto de História Oral deve conter necessariamente uma entrevista, mas, nem toda entrevista faz parte de um projeto de História Oral, posto que:

a entrevista em história oral é a sistematização dos processos organizados pela lógica proposta no projeto inicial. Entende-se por 
projeto o plano capaz de articular argumentos operacionais de ações desdobradas de planejamentos de pesquisas prévias sobre algum grupo social que tem algo a dizer. (MEIHY; RIBEIRO, 2011, p.13)

Consoante Veroni (1996) nas últimas décadas as Ciências Sociais e de natureza histórica vem se apropriando deste método e produzindo variados textos de cunho teórico-metodológico, pois:

[...] a história oral pode dar grande contribuição para o resgate da memória nacional, mostrando-se um método bastante promissor para a realização de pesquisa em diferentes áreas. É preciso preservar a memória física e espacial, como também descobrir e valorizar a memória do homem. A memória de um pode ser a memória de muitos, possibilitando a evidência dos fatos coletivos (THOMPSON, 1992, p. 17).

A memória realmente tem sido símbolo de luta e muita resistência por parte de historiadores tradicionais. De acordo com a citação acima o uso da História Oral se dará mediante a memória, em outros termos, é através dela que se recupera o passado para que seja apurada em algo útil e inteligível aos nossos objetivos, isto significa que é um relato de ações do pretérito reelaboradas no presente e servem também como constituinte de uma identidade coletiva.

As fontes extraídas desse método constituem o que podemos denominar de documentos pessoais. A narrativa deve ser sempre preservada para que não seja prejudicada a identidade do entrevistado. Por isso Portelli (1991, p. 45) explana:

[...] lo realmente importante es que la memoria no es un depósito pasivo de hechos, sino un activo proceso de creación de significados. Así la utilidad específica de las fuentes orales para el historiador no está tanto en la capacidad para preservar el pasado como en los câmbios mismos elaborados pro la memoria" [...] "Estos cambios revelan el esfuerzo de los narradores por darle un sentido al pasado y una forma a sus vidas y colocan a la entrevista y a la narración en su contexto histórico.

Destarte, mediado pela teoria de Portelli (1991), partimos do pressuposto que a fonte oral nos concederá visões e tornarão as pesquisas na área da História da Educação mais viva no intento de se averiguar como se procede as categorias estruturais da 
natureza histórica dos professores lhes concedendo vida através dos ecos de suas vozes e possibilita que o pesquisador compreenda-os e interprete-os a partir de uma escuta atenta sobre como era o contexto educacional de um determinado tempo histórico.

Neste próximo momento, far-se-á um entrelaçamento entre a História Oral como fonte para a História da Educação com o intuito averiguarmos a importância de ser explorada a subjetividade que compõe o universo dos docentes, tendo em vista que, estes criam e recriam suas representações ao redor de seus exercícios profissionais.

\section{O uso metodológico da História Oral na construção da identidade docente}

A construção da identidade docente é composta por um conjunto de fios que na maioria das vezes acaba se imiscuindo em um emaranhado de dimensões como a parte física e a emocional conjugando aspectos históricos e sociais ao longo das suas caminhadas. Neste sentido, para melhor compreendermos o que é a construção da identidade docente tomamos para nós que a:

Identidade profissional se constrói, pois, com base na significação social da profissão; na revisão constante dos significados sociais da profissão; na revisão das tradições. Mas também com base na reafirmação de práticas consagradas culturalmente que permanecem significativas. Práticas que resistem as inovações, porque prenhes de saberes válidos às necessidades da realidade. Identidade que se constrói com base no confronto entre as teorias e as práticas à luz das teorias existentes, na construção de novas teorias. Constrói-se também, pelo significado que cada professor, enquanto ator e autor confere à atividade docente no seu cotidiano, com base em seus valores, representações, em seus saberes, em suas angústias e anseios, no sentido que tem em sua vida o ser professor. Assim, como mediante sua rede de relações com outros professores, nas instituições de ensino, nos sindicatos e em outros agrupamentos. (PIMENTA \& ANASTASIOU, 2002, p.77)

O enxerto acima nos revela que a construção da identidade docente é tecida por diversas facetas que ao longo do tempo acaba influenciando na formação destes profissionais. Assim sendo, medrar a vida dos professores tende a revelar muito além de suas práticas cotidianas, das políticas educativas em que se embasam, mas sim, os percursos que os levaram a tornassem professores suscitando questionamentos e 
dúvidas. Posto isto, dentro deste mote a História Oral auxilia no processo de recordar e no uso do jogo da memória para a sua construção social.

No âmbito da História da Educação pesquisas com a inclusão deste aporte metodológico ganham cenário profícuo a partir de 1980, pois, até então as práticas escolares eram desveladas somente ancoradas em fontes de análise documental que se fundamentavam predominantemente nas políticas públicas e nas escolas pedagógicas. No entanto, na virada historiográfica, com a Micro-História e a Nova História Cultural, os sujeitos singulares da história ganham novos contornos, cenários e roupagens onde o sujeito é revalorizado em seu cotidiano, incluso, na história da formação de professores. Coadunado com as discussões deste período, é emergente os debates ao redor da crise de identidade da carreira profissional dos professores, posto que, acaba colocando os "professores no centro dos trabalhos educativos e das problemáticas da investigação." (NÓVOA, 2007, p.15).

Partindo das informações acima, as investigações que se amparam do método buscaram trazer à tona novos debates, temas e problemáticas no interior das diversas instituições com o intuito de possibilitar análises ao redor das circularidades das singulares culturas tecidas no interior e exterior das escolas em um processo de rupturas e continuidades que muitas vezes não se encontram atinentes nos livros do universo pedagógico.

Conquanto, a história oral se ampara do uso de entrevistas em que se desdobram de um projeto de pesquisa vindo a se tornar um veio para avaliarmos e interpretarmos as práticas escolares, em específico, para este momento: a formação de professores. Assim, a História Oral descortina movimentos desvalorizados tecendo novas perspectivas a diferentes testemunhos no empenho de averiguarmos os itinerários de formação destes por meio da evocação da memória.

A palavra memória é constituída de muitas terminologias, em suma, é o ato de recordar algo, que por sua vez, pode ter sido um vestígio ou uma lembrança de outrora. Para tanto, é fundamental que referendamos a memória como uma fonte para as investigações em história com o objetivo de favorecer na interpretação dos fatos, e que por sua vez, nos forneça credibilidade para exposição destes. 
A memória segundo Burke (2000) pode ser vista como uma fonte histórica. Halbwacks (1990), em seu livro a Memória é Coletiva, nos revela que o tratamento dado a memória por alguns autores foi em linha contraposta a história. Na visão de Norra (1993) a:

\begin{abstract}
A memória é a vida, sempre carregada por grupos vivos e, nesse sentido, ela está em permanente evolução, aberta à dialética da lembrança e do esquecimento, inconsciente de suas deformações sucessivas, vulnerável a todos os usos e manipulações, suscetível de longas latências e de repentinas revitalizações. A história é a reconstrução sempre problemática e incompleta do que não existe mais. A memória é um fenômeno sempre atual, um elo vivido no eterno presente; a história, uma representação do passado. Porque é afetiva e mágica, a memória não se acomoda a detalhes que a confortam; ela se alimenta de lembranças vagas, telescópicas, globais ou flutuantes, particulares ou simbólicas, sensível a todas as transferências, cenas, censura ou projeções. A história, porque operação intelectual e laicizante, demanda análise e discurso crítico. A memória instala a lembrança no sagrado, a história a liberta, e a torna sempre prosaica. (Norra, 1993, p. 9)
\end{abstract}

Norra (1993) nos revela que tanto a memória como a história estariam intrínsecas, principalmente, no que diz respeito, ao desenvolvimento da memória nacional. Ricoeur (2000) aponta que a relação da história e memória ocorre permeado por um diálogo o que vem a se diferenciar dos anteriores autores citados, assim sendo, para o pesquisador, o estudo da memória considera importante os esquecimentos, ainda que, "ver uma coisa é não ver outra. Narrar um drama é esquecer outro. (RICOEUR, 2007, p. 459). Para Le Golf a memória tende a "conservar certas informações, remetemos em primeiro lugar a um conjunto de funções psíquicas, graças às quais o homem pode atualizar impressões ou informações passadas, ou que ele representa como passadas.” (LE GOLF,1994, p.419)

Tanto Burke (2000), Halbwacks (1990), Norra (1993) e Le Golf (1994) nos manifestam premissas a respeito dos seus apontamentos teóricos sobre a relação da memória com a história, tendo em vista que, por muito tempo estudos realizados através do uso memória foram preconizados com desdém pelos historiadores clássicos por achálos sem veracidade, todavia, a historiografia ao longo de tempo passa a considerar outras estruturas de narrativas para escrever a história que antes não eram consideradas 
possíveis como o caso das narrativas orais que são advindas da memória.

A memória pode ser considerada como um indício histórico, embora, não se encontre escrita pode nos ajudar a compreender os vestígios do passado porque é uma prova do que foi experienciado por um indivíduo nos levando a reelaborar compreensões em torno de fatos já acontecidos e mediados por entrevistas elaboradas dentro de um projeto de pesquisa.

Nas entrevistas, em específico, as realizadas com os professores se faz mister detectar através da escuta atenta de suas narrativas orais as influências históricas e educacionais da época, em razão de que, estas construções são dotadas de significados num intento de cotejar as diversas apropriações da realidade com o que de fato aconteceu. Em outras palavras, embora se saiba do contexto histórico educativo da abordagem se compreende que há uma grande distância entre o que a legislação determina e o que de fato ocorria nos intramuros escolares. Aqui cabe ecoar a fala de Lucília Delgado (2006, p.15) que nos revela que a História Oral "é um procedimento metodológico que busca, pela construção de fontes e documentos, registrar, através de narrativas induzidas e estimuladas, testemunhos, versões e interpretações sobre a História em suas múltiplas dimensões."

Para tanto, a História Oral pode ser um caminho quando não encontradas respostas nos documentos para a problemática de pesquisa, principalmente, quando se almeja a compreender como foi tecida a identidade docente em uma determinada instituição, pois, a sua prática desencadeada ocorre com sua relação nas inferências tecidas entre passado pedagógico e educativo e com o seu cotidiano. Como nos revela Candau (2014) a memória e a identidade são relacionais, ou seja, uma existe em função da outra, neste sentido, a construção de aspectos alojados na memória docente oportuniza o conhecimento dos antepassados de sua formação suscitando novos elementos e inauditas problematizações de estudos com o intuito de recuperar as vozes que foram silenciados por longos anos pela História Tradicional.

Consoante Demartini (2001) a História Oral é um método fundamental para a composição histórica da profissão docente, visto que, viabiliza pensar concretamente com relação as suas práticas, suas lutas de classes, as suas experiências e suas ideologias, pois, 
as fontes orais possibilitam apreender não só fatos desconhecidos, mas também representações de diferentes personagens envolvidos no processo educacional - a visão dos professores, dos pais, dos alunos, dos diferentes grupos étnicos etc. - que tem sido muito pouco consideradas nas reflexões sobre questões educacionais. (DEMARTINI, 2001, p.122)

Ainda reforçando a fala de Demartini (2001) Selva de Guimarães Fonseca (2006) nos informa que:

“[...] o registro da vida dos professores [e de suas memórias], de suas maneiras de ser e ensinar, situa-se neste campo movediço em que se cruzam os modos de ser do indivíduo e o mundo social, as instituições e os diferentes atores, grupos e conflitos sociais que fazem parte de suas trajetórias. "(FONSECA, 2006, p.35)

A partir da fala de Fonseca (2006) incrementamos a dizer que as entrevistas realizadas com docentes, situadas dentro do campo da História da Educação nos ajudam em uma análise a partir de duas operações epistemológicas: a de compreender e a de interpretar, as suas trajetórias pessoais através do tempo em que eram regentes de classes, analisar suas experiências práticas em sala de aula, os valores por eles internalizados, seus medos, suas dificuldades, seus desafios, do mesmo jeito que, os princípios religiosos, o núcleo familiar e a sua escolarização até a sua ascensão em cursos superiores, quer seja, seus percursos formativos coadunados com suas captações de significados acerca do mundo educacional e tecidos ao redor de suas experiências em consonância com educação brasileira da época.

Entrementes, o pesquisador que trabalha com as narrativas orais deve ter cuidado para observar se as práticas escolares descritas nas narrativas dos docentes são práticas já consolidadas ou suas informações realmente trazem substrato para o objeto de estudo. Assim sendo, essa característica é importante a ser avaliada pelo pesquisador da História da Educação que trabalha com este método de pesquisa. Observado este aspecto, aponta-se que a História Oral é um instrumento rico porque dá a possibilidade de que conheçamos o que os professores vivenciaram, diziam e pensavam nos dando pistas para que se averigue os seus registros de memórias no intento de compreendermos e interpretarmos as suas representações de experiências passadas. 
Inegavelmente, o professor é um sujeito dotado de historicidade e de grande significado para o âmbito educacional, assim sendo, os sujeitos apresentam traços singulares, embora, suas ações individuais possam ser representadas por experiências coletivas. Partindo disso, entra em ação a História Oral quando estes são interrogados a fim de que seja captado em suas narrativas os seus significados construídos em torno de suas experiências em contextos que são difíceis de serem compreendidos por falta substancial de fontes históricas.

Nesse limiar, compreendemos que a História Oral é um recurso da modernidade que nos oferece uma gama de possibilidade se observarmos os ângulos de um sujeito mediado por conversas com o intuito de prevalecer conexões entre o passado, presente e futuro.

Na voz de Meihy essa afirmativa é melhor exemplificada, pois, se trata de um:

(....) recurso moderno usado pra elaboração de documentos, arquivamento e estudos referente à vida social de pessoas. Ela é sempre uma história do tempo presente e também conhecida por história viva. Como história dos contemporâneos, a história oral tem que responder a um sentido de utilidade prática e imediata. (MEIHY, 1996, p.13)

Destarte, como nos revela Meihy (1996) trabalhos com História Oral precisam fornecer um sentido, visto que, através da memória é possível trazermos à tona as lembranças de professores num movimento que vai de suas particularidades para o âmbito geral. Assim sendo, por meio do que descobrimos na fala do outro podemos perceber casualidades que ocorrem em nós enquanto pesquisadores possibilitando a compreensão da própria prática em muitas situações, ou seja “o estudo da memória deve inserir-se numa tentativa de compreender o lugar onde o sujeito é produzido, pois lembrar é refazer, reconstruir, repensar, com ideias e imagens de hoje, as experiências do passado" (GUSMÃO, 2004, p. 31).

Além disso, à medida que os sujeitos vão narrando suas experiências, crenças e expectativas vão comunicando os seus desejos ou projetos que estão por ser realizados, isto significa que, em muitas situações é difícil diferenciar o que já viveu com o que está por viver.

Em uma perspectiva geral apoderar-se das narrativas dos professores é um 
instrumento potente porque não basta somente dizer que o docente deve se apropriar das experiências de seus discentes se muitas vezes o próprio currículo educacional não pensa que os professores são sujeitos que fazem a história nacional. Pois, para Greenne (1995).

(..) o professor é tratado como se não tivera vida própria, como se não tivera corpo, uma linguagem, uma história ou uma interioridade [...] Sua biografia pessoal foi esquecida, assim como as diferentes maneiras com as quais expressa a si mesmo através da linguagem, dos horizontes que percebe, as perspectivas com as quais olha o mundo. (GREENNE,1995, p.84).

Consoante a fala de Greenne (1995) ele nos remete ao fato que a historicidade dos professores acabou sendo esquecida o que leva a estes a realizarem muitas vezes suas práticas de modo automático sem os levarem a refletir, melhor dizendo, realizam ações muitas vezes em função do social, do que os livros dizem, do que a mídia aponta, do que as gestões estabelecem para os docentes, contudo, é algo tão mecânico que acabam esquecendo-se da sua própria identidade, historicidade, liberdade de agir, bem como, a faculdade de se reinventar a todo o momento permanecendo incrustados em práticas verticais, tradicionais e domesticadoras. Tal atitude acaba por fim sendo traumático para os futuros professores que estão sendo formados. Assim, emerge o seguinte questionamento: Afinal, como alguém poderá delinear uma nova identidade aos seus educandos se ele não consegue nem definir a si mesmo? Neste contexto de que expusemos concatenamos com a fala de Pérez Gomez (1992) para respondermos a pergunta acima, pois, o autor nos desvela sobre como é importante que o professor busque e restaure a sua racionalidade prática porque ele precisa ser o:

(...) sujeito da análise que faz de seu próprio cotidiano, implicando a imersão consciente do homem no mundo de sua experiência, num mundo carregado de conotações, valores, intercâmbios simbólicos, correspondências afetivas, interesses sociais e cenários políticos. (PÉREZ GÓMEZ, 1992, p.103).

O autor da citação nos deixa bem claro que mediado pela reflexão-ação é viável que o professor dentro do discurso elaborado nas entrevistas possa compreender e refletir e até mesmo transformar a sua situação pedagógica. Por fim, podemos ressaltar 
que as descobertas ao longo das entrevistas não podem ser consideradas como somente uma descrição do que é vivido, e sim, a produção de um conhecimento que como sujeitos experimentaram e experienciam o mundo.

Partindo da concepção de Nóvoa (1992) a formação docente acontece ao longo de toda sua vida, assim sendo, o professor, adquire durante sua vida visões de mundo inerentes a sua prática, contudo, muitas vezes a categoria não toma consciência de sua representatividade. Na realidade a grande maioria dos professores não compreende os sentidos de sua construção nacional. Neste enfoque, o uso do método é uma alternativa que possibilita aos docentes perceberem os aspectos obscuros impetrados nas políticas educacionais e nos currículos educacionais, tendo em vista que, "a História Oral, pode iluminar lugares ocultos da vida escolar, apontar formas sutis de resistência e sublinhar os efeitos de currículos, normas e diretrizes." (GUSMÃO, 2004, p. 31)

Esmiuçando a fala de Gusmão (2004) o uso da História Oral é de essencial acuidade porque visa a valorizar as especificidades e singularidades da cultura material da escola e dá voz para individuos inviabilizados até então, e assim:

Os documentos redigidos a partir das histórias de vida são, muitas vezes, extremamente vivos: neles descobrem-se pontos de vista originais sobre experiências pessoais, até mesmo pontos íntimas em detalhes. (...) é uma maneira de recolocar o indivíduo no social e na história: inscrita entre análise psicológica individual e dos sistemas socioculturais, a história de vida permite captar de que modo indivíduos fazem a história e modelam sua sociedade, sendo também modelados por ela. (LAVILLE\&DIONNE, 1999, p.159)

Laville\&Dionne (1999) nos aponta que os documentos criados através das histórias de vida são vivos, pois, se pensarmos bem, as histórias de vida dos docentes são derivadas muito antes da realização dos cursos de licenciatura, ou seja, dimana das suas histórias pessoais. Os motivos de serem, estarem e atuaram na profissão é um ato muito importante e atual no empenho de que eles se enxerguem através de suas imagens, de suas e das práticas adquiridas ao longo do tempo, das suas trajetórias. Assim sendo, "compreender como cada pessoa se formou é encontrar as relações entre as pluralidades que atravessam a vida. Ninguém se forma no vazio. [...] Ter acesso ao modo como cada pessoa se forma é ter em conta a singularidade da sua história" (MOITA, 1995, p. 114-115). 
Em linhas conclusivas, trabalhar com a História Oral para captar a identidade dos professores vai para além do que está escrito nas legislações, nos currículos, pois, trabalha no campo da subjetividade e de como estes constroem suas representações acerca do passado e presentificam suas vivências que foram emergentes em um dado contexto histórico, a fim de que, se possa apreender a sua construção cultural e identitária averiguando as suas marcas culturais impressas nas práticas escolares da caixa preta da escola.

\section{Conclusão}

Através deste ensaio podemos compreender que o aporte metodológico cerceado da História Oral para construir ou reconstruir a identidade profissional dos professores é um campo fértil porque possibilita que o profissional se enxergue e perceba a sua representatividade e os sentidos a ele atribuído no cenário educativo.

Ao trabalharmos com a construção identitária docente instrumentalizado pela História Oral é importante levar em consideração que o docente está imerso na articulação do eu pessoal com a do profissional. Suas memórias são acionadas, pois, junto com a sua vida pessoal imiscui-se com a sua vida pessoal que é alicerçada de valores, regras, normas, hábitos cristalizados que se repercute em suas práticas escolares.

Ademais, a História Oral possibilita que se teça elos entre a sua formação e suas práticas colocando-o em posição de protagonista da sua história, que é individual, mas, que vem a se entrelaçar com a dos demais, tendo em vista que, ele lida coma formação de outras pessoas. No entanto, é um veículo importante e imprescindível para pesquisadores que pretendem compreender os desafios da profissão, os medos, as incertezas, o processo de sua formação e de seus formadores e a sua construção enquanto profissional.

Portanto, pensar e repensar a prática pedagógica docente é um exercício substantivo para a classe docente porque somos um misto do que a nós é contado, do que nós falamos porque somos os personagens de uma história que aconteceu em um tempo, mas, para que isso ocorra é vital que observemos as subjetividades de suas vidas. A História Oral pode trazer à tona aspectos da identidade docente quando desvelamos as 
prováveis contribuições que o uso desta metodologia traz na tentativa de interpretamos os aspectos sobre a formação de professores.

O ensaio atentou para a importância do uso da História Oral no ensejo de suscitar aspectos da identidade docente. Assim sendo, a formação dos profesores tem adquirido nas últimas décadas debates calorosos e indubitavelmente vem se constituindo em uma área de grande importância para as investigações acadêmicas. No entanto, é notório que mesmo com um imenso acervo de divulgações científicas pouco se tem presenciado com relação as mudanças efetivas no processo de formação destes profissionais, ou seja, raramente estas ultrapassam os extramuros da academia gerando descontentamento por parte dos agentes constituintes deste processo, assim, pensar, refletir e analisar ao redor da formação de professores e de seu processo de constituição deve ser um tema que precisa estar em pauta no dia.

Outrossim, os documentos à medida que são transcritos ganham organicidade, pois, este aporte metodológico tende a valorizar o indivíduo como o personagem principal de sua história. Ao lidarmos com a subjetividade é imprescindível vislumbrarmos que ela é embasada na experiência de vida de alguém, visto que, o agente pesquisado narra os fatos de sua vida tanto na esfera pessoal como social. Em linhas gerais todos nós apresentamos histórias de vida que são testemunhos edificados consoante as nossas experiências, o que por si só, constitui um grande campo para a concretização de qualquer pesquisa histórica, assim, o aporte oral em ambientes institucionais serve como um estatuto para analisarmos e captarmos nuances ainda não desveladas nos documentos existentes.

Neste ensejo de informações, a possibilidade do uso das narrativas orais em pesquisas na área da História da Educação visa a nos revelar as experiências destes docentes que atuaram e alguns que continuam atuando na educação brasileira, pois, quando indagamos acerca da construção da identidade profissional dos docentes se anseia por meio da problematização detectarmos a sua identidade formativa tecida à luz do presente para representarmos o passado de suas experiências.

Assim, conclui-se que ela serve como um instrumento valioso para que se possa aprofundar os pontos convergentes e divergentes destes profissionais, bem como, alterar o estatuto destes em questões que precisam ser modificadas. A História Oral 
empregada dentro desta categoria profissional docente vem buscando a gênese das problemáticas instaladas dentro dos sistemas educativos para assim advogar em prol de uma educação de mais qualidade.

\section{Referências}

ALBERTI, Verena. Manual de História Oral. Rio de Janeiro: FGV, 2004.

BURKE, Peter. História como memória social. In: . Variedades de história cultural.

Rio de Janeiro: Civilização Brasileira, 2000. p. 67-89.

CANDAU, Joël. Memória e identidade. Trad. Maria Leticia Ferreira. 1. ed. São Paulo: Contexto, 2014.

CAMARGO, Aspásia. História oral e política. In: FERREIRA, Marieta de Moraes (Org.). História oral e multidisciplinaridade. Rio de Janeiro: Diadorim, 1994. p.75-99.

DELGADO, Lucília de Almeida Neves. História Oral, memória, identidades. Belo Horizonte: Autêntica, 2006.

DEMARTINI, Zeila de Brito Fabri (2001). Crianças como agentes do processo de alfabetização no final do século XIX e início do século XX. In: MONARCA, Carlos (Org.). Educação da Infância Brasileira: 1875-1983. Campinas: Autores Associados, 2001, pp. 121156.

FERREIRA, Marieta de Moraes (org). História oral e multidisciplinaridade. Rio de Janeiro: FINEP/Diadorim, 1994. 157p.

FERREIRA, Marieta de Moraes e AMADO, Janaína (Orgs.) Usos e Abusos da História Oral. Rio de janeiro: FGV, 1998.

FONSECA, Selva Guimarães. Ser professor no Brasil: história oral de vida. $3^{\mathrm{a}}$ ed. Campinas/SP: Papirus, 2006.

GREENE, Maxine, El Professor como Extrangeiro. In: LARROSA, Jorge (org.). Déjame que te Cuente. Barcelona; Editorial Laertes, 1995. P.81-130

GUSMÃO, Emery Marques. Memórias de quem ensina História: cultura e identidade docente. São Paulo: UNESP, 2004.

HALBWACHS, M. A memória coletiva. São Paulo: Vértice, 1990.

JOUTARD, Philippe. "Desafios à história oral do século XXI". In: FERREIRA, Marieta de Moraes; FERNANDES, Tania Maria; ALBERTI, Verena (orgs.). História Oral: Desafios para o 
século XXI. Rio de Janeiro: Ed. Fiocruz, Casa de Oswaldo Cruz e FGV/CPDOC, 2000, p.31-45.

LAVILLE, C.; DIONNE, J. A construção do saber: manual de metodologia da pesquisa em Ciências Humanas. Porto Alegre: Editora UFMG, 1999.

LE GOFF, Jacques. História e memória. Campinas: Ed. UNICAMP, 1994.

MATOS, J. S.; SENNA, A. K. História Oral como fonte: problemas e métodos. Rio Grande, v. 2, n. 1, p. 95-108, 2011.

MATOS, J. S.; SENNA, A. K. O historiador-docente entre as práticas e os saberes das políticas de formação continuada. II Seminário de história política: olhares além da prática. 16 e 17 de junho de 2011 - GT História Política ANPUHRS - FURG - PUCRS, 2011.

MEIHY, José Carlos S. Bom. Manual de história oral. São Paulo: Loyola, 1996.

MEIHY, José Carlos Sebe Bom; RIBEIRO, Suzana Lopes Salgado. Guia prático de história oral: para empresas, universidades, comunidades, famílias. São Paulo: Contexto, 2011.

MOITA, Maria da Conceição. Percursos de formação e de transformação. In: NÓVOA, António (Org.). Vidas de professores. Portugal: Porto, 1995.

NORRA, Pierre. Entre memória e história: a problemática dos lugares. Projeto História, São Paulo, n. 10, p. 7-28, 1993.

NÓVOA, A. Formação de professores e profissão docente. In: NÓVOA, A. N. (Coord.). Os Professores e a sua Formação. Lisboa: Publicações Dom Quixote, 1992.

NÓVOA, António (Org.). Vida de Professores. Porto: Porto Editora, 2007.

PÉREZ GÓMEZ, Angel. O pensamento prático do professor: a formação do professor como profissional reflexivo. In: Nóvoa, António. Os professores e a sua Formação. Lisboa: Dom Quixote, 1992. P.93-114.

PIMENTA, S. G., \& ANASTASIOU, L. G. C. (2002). Docência no ensino superior. São Paulo: Cortez Editora.

PORTELLI, A. "The time of my life: functions of time in oral history" in: The death of Luigi Trastulli and other stories: form and meaning in oral history, Nova York, State University of New York, 1991. In: RIBEIRO FENETON, D. et al. (Orgs.). Muitas memórias, outras histórias, San Pablo: Olho d’Água. Traducido al portugués por: Helen Hughes y Yara Aun Khoury, San Pablo (PUC-SP), 2004.

PORTELLI, Alessandro. Aos cinquenta anos: uma perspectiva internacional da história oral. In: ALBERTI, Verena et al. (Orgs.). História Oral: desafios do século XXI. Rio de Janeiro: Editora Fiocruz/Casa de Oswaldo Cruz /CPDOC - FGV, 1998. p. 47 - 65. 
RICOEUR, Paul. Tempo e narrativa. Campinas, SP: Papirus, 1994.

THOMPSON, Paul. A voz do passado. São Paulo: Paz e Terra, 1992.

THOMSON, Alistair. Aos cinquenta anos: uma perspectiva internacional da história oral. In: ALBERTI, Verena et al. (Orgs.). História Oral: desafios do século XXI. Rio de Janeiro: Editora Fiocruz/Casa de Oswaldo Cruz /CPDOC - FGV, 2000. p. 47 - 65. histórica. Brasília: UnB, 2007(b).

Recebido em: 10/02/2020

Parecer em: 26/08/2020

Aprovado em: 06/03/2021 